\title{
Mobile Application Design to Control Human Resources Performance in a Technology Organization
}

\author{
Alexi Delgado ${ }^{1}$, Angie Maite Del Rio Chillcce ${ }^{2}$, Chiara Carbajal $^{3}$ \\ ${ }^{1}$ Mining Engineering Section, Pontificia Universidad Católica del Perú, Lima-Peru, kdelgadov@pucp.edu.pe \\ ${ }^{2}$ Systems Engineering Program, Universidad de Ciencias y Humanidades, Lima-Peru, angdelrioc@uch.pe \\ ${ }^{3}$ Administration Program, Universidad de Ciencias y Humanidades, Lima-Peru, ccarbajal@uch.edu.pe
}

\begin{abstract}
At almost the majority of companies in Lima, employees record their arrival and departure times by e-mail, facing this, and to optimize that time, a user-friendly and secure mobile application has been created. The methodology used was Balsamiq, by means of which the Android system was developed, whose main function is to give employees a mobile application where they can register activities, projects in courses and record their working hours. The mobile application will serve as a solution, since it is user-friendly and can be used by several employees at the same time. In this way, what is sought is to have an application that allows any company (without distinction of the magnitude that this may have), to possess a system to monitor the hours and activities of its employees, without the need to invest an initial fee to have a similar implementation.
\end{abstract}

Key words :Android operating system, Balsamiq, Human resources, Mobile application.

\section{INTRODUCTION}

In some countries, the Supreme Court has sentenced companies to implement a system or application that controls the hours of their workers who work overtime, and also supervises those who do not. The Court explained that: "failure to keep records, or not to inform workers about hours worked on special shifts, or to perform merely formal or documentary obligations, constitutes a minor misdemeanor" [1].

Meanwhile, Peru in 2018 has had a rise in the vast majority of companies which have been increasing. And as a consequence of this, companies live a period of uncertainty in proportion to having a control of the hours worked by the company's employees [2]. How is it possible to have a control of the hours worked? In which manner do we know if our workers are carrying out the work assigned to them? Are they complying with their work schedules? These are some of the questions we ask ourselves [3].

In this regard, it has been stated that in Lima, according to a report by the National Institute of Statistics and Informatics (INEI by its Spanish acronym), between February and April of this year, 112,500 Lima residents worked more than 80 hours a week, in other words, more than 11 hours in one day, seven days a week [4].
Confronted with this lack of control, the Balsamiq methodology will be used, since it is a program that provides us with quick and easy access to the objectives set out in the present study [5]. Within this methodology there are 4 stages [6], starting with the development of prototypes, followed by the elaboration of the sketch. In the third stage the design application will be developed, meaning that all screenshots of the application will be presented. Finally, the fourth stage is the test user, in this stage it can be seen that the user checks the effectiveness and can implement new features within the application as well as give any feedback that may suggest for the application effectiveness prior to market release [7].

The goal of the present study is to obtain an application that allows any company (large or small) to have access to a system for controlling the hours and activities of its employees, without the need to invest an initial fee to have a similar application [8]. Thus, Omega will be an effective time controller, easy to understand that will provide help to get staff used to the current way of working, as well as allowing various procedures.

The structure of this research consists of the methodology explained in section 2, which is followed by the application with the tool indicated. The results and discussions are shown in section 3. Finally, section 5 presents the conclusions obtained from the research.

\section{METHODOLOGY}

In this research work, the design of a mobile application will be presented with the objective of organizing, structuring and producing an optimal prototype for the adaptation of the mobile application; below, the stages for the creation of the interface will be detailed [9].

\subsection{Prototype Development}

This stage consists of the design of the first model of how the software will work, which is why it is the first phase of its life cycle. There are several techniques for this process, among which the following are emphasized:

- Develop this prototype in several languages.

- To adjust elements of the software, taking advantage of it and putting parts of the product back together to carry out a feasible solution.

- Assign the user to intervene in the tests in order to understand the progress of the result, so that the system must answer to the user. 
It is of utmost importance to clarify that the design of the elaborated application is a structure in order to establish certain requirements that are essential for the advancement of the subsequent cycles of software development [10].

\subsection{Sketch Elaboration}

At the moment of elaborating a new project, the usual thing is to prepare a draft, design or sketch, in order to have a visual reference on our interface, in that way we will have a help at the moment of creating the application, since it will be as similar as possible to the outline done before. Meanwhile on paper we do changes, delete, improve and implement ideas, then this sketch will become the basis of the final project. This process is known as Wireframing as it serves to create the interface distribution [11].

\subsection{Mobile application function (Design application)}

At this stage what is sought is to know the position and practice of each user, is the stage in which some sketches and flexible models are developed for the production of the mobile application, thus achieving a sketch quickly. The aim here is to have a better structure than what was already planned, taking into consideration and correcting certain errors, we can incorporate improvements to the sketch.

Likewise, it is necessary to keep in mind that the application requires a friendly and interactive design aspect for the user that helps to facilitate its presentation with the final user without losing its fluidity, arriving to have a presentable prototype.

\subsection{Test Users}

This stage takes place when the mobile application is not yet on the market. In this way, a test study is carried out with users to verify the correct functioning of the application, receiving complaints, suggestions and obtaining feedback before the introduction to the target audience.

\section{APPLICATION}

Once the stages of the methodology have been developed, it is considered pertinent to provide the study with a brief definition of key terms for those who are introduced to the subject and/or to share the same basic language with the reader of this research. The terms considered are the following:

\section{A. Mobile application}

Software application that can be downloaded and accessed quickly from a mobile phone or Tablet [12].

\section{B. Android operating system}

It is an operating system based on the multiplatform Linux, which is a free access system for those who have intelligent mobile devices (Google bought its system in 2005) [13].

\section{C. $A P K$}

It is a package for the Android operating system; and is used to set up and install components packaged on the Android platform for a mobile phone and Tablet [14].

\section{Java}

It is a programming language, it is fast, secure and reliable [15].

Once this terminology has been described, we will develop the steps of the methodology by applying it to the study proposal.

\subsection{Prototype Development}

Android Studio is a development interface. As a matter of fact, it is a kind of working desktop for a developer. This is where our project is located, its folders, files and everything that is needed to complete the application. In a convenient way, Android Studio has been created by Google and has been exhibited a few months ago, this means that it is not an instrument or tool with years of antiquity, that is to say it is a current and modern tool, which has been created by the same creators of the Operating System [16], as shown in Figure 1.

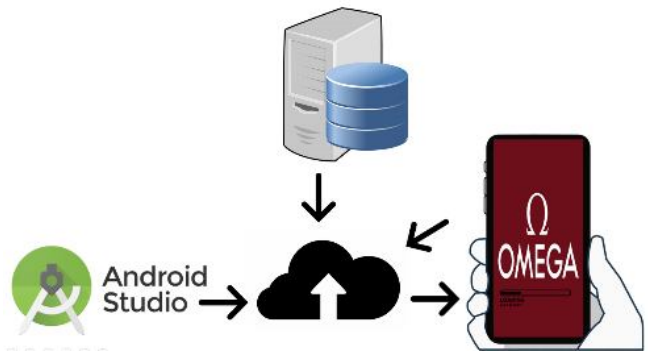

Figure 1: Android Studio and Cloud Distribution

\subsection{Sketch Elaboration}

This mobile application was created to provide a solution and have control over the activities and hours worked by employees of a company, it has also been considered beneficial to replace unnecessary emails (Figure 2) and to promote the use of a safe and reliable mobile application.

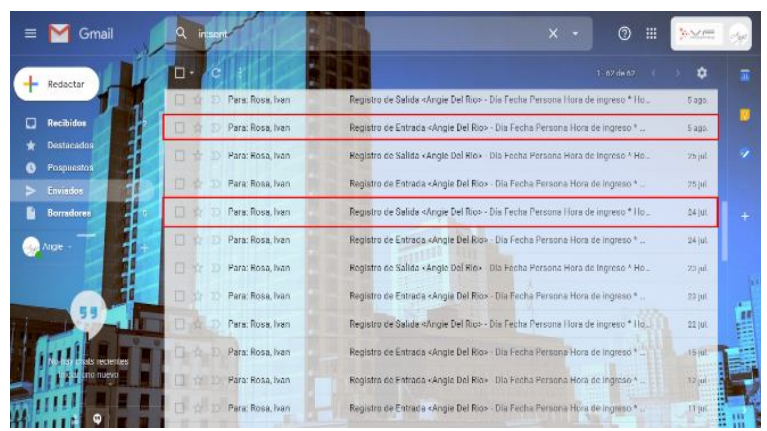

Figure 2: Gmail e-mails to record activities and hours worked

The logo of the mobile application "OMEGA" will occupy the screen of the mobile phone once the application is started, as can be seen in Figure 3. Furthermore, the user will be able to $\log$ in by means of a previous registration of the institutional mail of the company where he works with a password of the contributor's choice (Figure 4), this will lead us to the information of the user. 


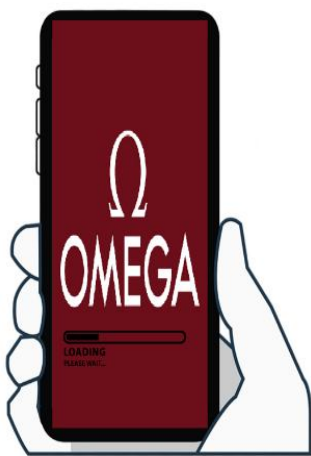

Figure 3: Home Screen

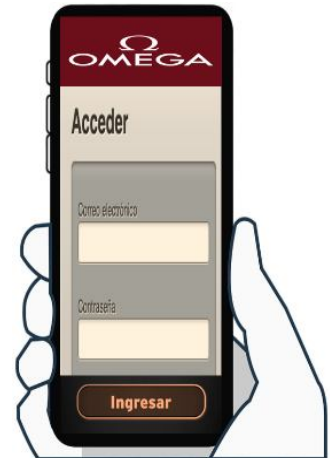

Figure 4: $\log$ in Screen

\subsection{Mobile application function (Design application)}

In this stage, all the screens of the application will be presented in addition to those already mentioned in the previous phase. The main screen of the user can be seen in Figure 5, this screen manages to collect both personal user data and data from their projects, either these are completed or currently in process.

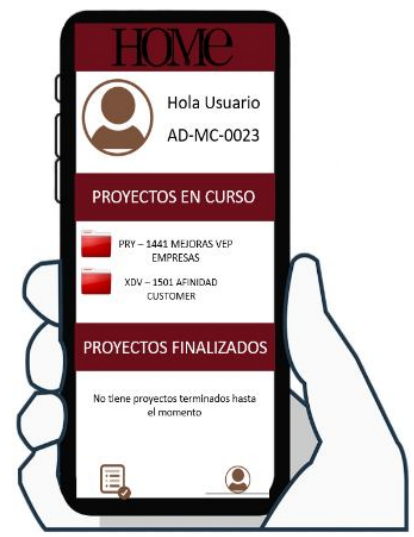

Figure 5: Main Screen

After that, the activities of the users are visualized as shown in Figure 6, in this section the partner can import data from new projects (or activities) including the duration of their activities and the day of start.

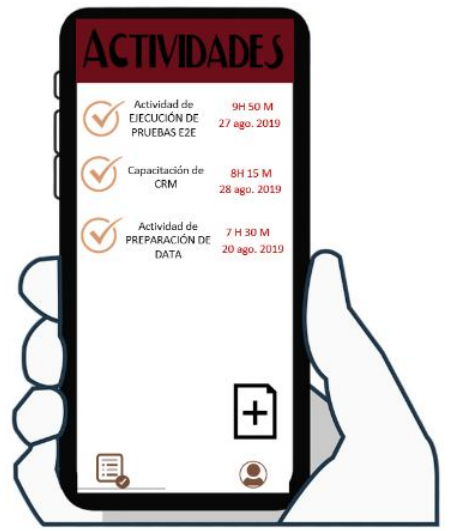

Figure 6: Activities Menu

In Figure 7 you can see the display appearance when adding this information; moreover, as an added value, it has been considered appropriate that the different activities can be grouped according to the category that the collaborator believes is most convenient for faster access when required. This will also allow the avoidance of repetitive/constant mails for the recording of the time of arrival and departure, together with a suitable report of the activities performed.

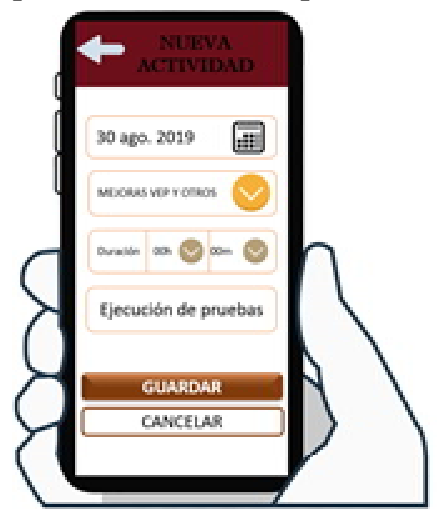

Figure 7: New Activities Registration

\subsection{Test Users}

Table 1 presents the explanations of the user functions according to the screens design observed in phase $\mathrm{C}$ of this application.

Table 1: Specifications of the functions of the control of the activities of the user

\begin{tabular}{|c|l|}
\hline Screen Design & \multicolumn{1}{|c|}{ Description } \\
\hline Main Screen & $\begin{array}{l}\text { The user will see all the information of } \\
\text { the current as well as the completed } \\
\text { projects. }\end{array}$ \\
\hline Activities menu & $\begin{array}{l}\text { The user will be able to control his/her } \\
\text { assistance, the hours worked and the } \\
\text { activities carried out during the day. }\end{array}$ \\
\hline $\begin{array}{c}\text { New Activities } \\
\text { Registration }\end{array}$ & $\begin{array}{l}\text { The user will have access to add new } \\
\text { activities. }\end{array}$ \\
\hline
\end{tabular}

\section{RESULTS AND DISCUSSIONS}

\subsection{About the Case Study}

The objective was to design a mobile application to control the hours and days worked by an employee within the company in order to avoid unnecessary emails when registering the time of arrival and departure, together with the activities performed, a situation that has been occurring as shown in Figure 8.

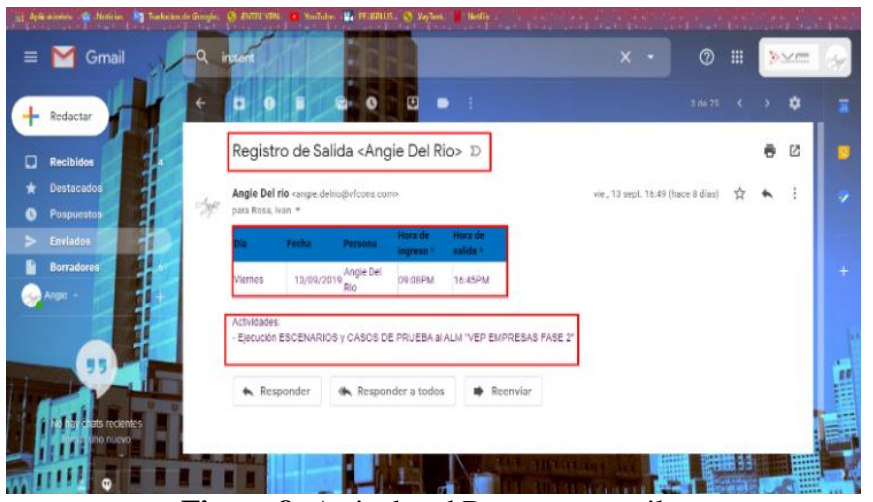

Figure 8: Arrival and Departure emails 
The proposed application will be used when an employee (the user) completes his or her workday, so they will be able to place the activities performed on that day and how many hours they have worked. The mobile application will serve as a solution to the spam mentioned in addition to being a continuous source where the user can be informed about the hours worked and can ask for remuneration if necessary. Also, the benefit of this application is noted to be able to be used without distinction by different employees that may be in a company, as it is user-friendly, and can be used by many employees at once.

\subsection{About the Methodology}

The results and discussion about the methodology are presented in Table 2.

Table 2: Results and discussions about the methodology

\begin{tabular}{|c|c|}
\hline \multicolumn{2}{|r|}{ Balsamiq Mockups } \\
\hline 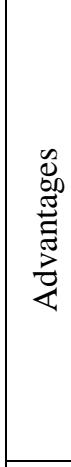 & $\begin{array}{l}\text { The first advantage to be highlighted is the possibility of } \\
\text { an evolution of a first slate sketch of a new screen } \\
\text { through a model made with Balsamiq in a finished } \\
\text { interface. As well as the fact that it reports that the } \\
\text { executable prototypes delivered by the development } \\
\text { team gave it a good idea of the state of implementation. } \\
\text { It allowed the project developer to verify that the agreed } \\
\text { functionality had been performed as desired and to plan } \\
\text { the subsequent interaction [17]. In addition, other } \\
\text { potential advantages are reduced product development } \\
\text { and support costs [18]. }\end{array}$ \\
\hline 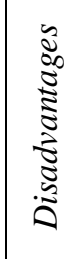 & $\begin{array}{l}\text { One disadvantage is that it generally requires a } \\
\text { facilitator, meaning someone who has a comprehensive } \\
\text { understanding of the application and can adequately } \\
\text { demonstrate it to the test participant [19]. It takes a long } \\
\text { time to create, and it is not effective for requirements } \\
\text { gathering [20]. }\end{array}$ \\
\hline 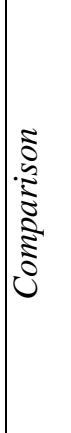 & $\begin{array}{l}\text { In the paper "Cloud-based Web Application with NFC } \\
\text { for Employee Attendance Management System" the } \\
\text { following method was used: Software Developer Life } \\
\text { Cycle, which is a process used to produce high quality } \\
\text { software that meets customer expectations within time } \\
\text { and cost estimation [21]. The reason for the increase in } \\
\text { the proposed time attendance management system is } \\
\text { described in a series of seven main phases consisting of } \\
\text { planning, analysis, design development, testing, } \\
\text { implementation, and maintenance [22]. }\end{array}$ \\
\hline
\end{tabular}

The difference between Balsamiq and Developer Life Cycle Software is that the last one serves as a prototype strategy, in the same way for a unified software development process [23]. However, Balsamiq serves as a model of the project or application.

\section{CONCLUSIONS}

This paper was proposed to create a mobile application to control the activities and hours performed, so that users (in this case employees of the company) have access to a secure and trusted application.

In order to achieve the implementation of this mobile application for the collection of activities and working hours, Android Studio has been used, as it provides and facilitates the creation of the mobile application, which is also connected to Java. The BALSAMIQ methodology helped to have a perspective of what we wanted within the application, both the design and the functionalities. It has also been demonstrated that the application of this methodology in cases such as the present is successful.

Finally, the mobile application will have precise and simple resources, thus providing the user with a simple tool to save everything necessary such as hours worked and activities. Likewise, it will serve the company by providing information regarding the activities that are executed, identifying which are the most productive areas and personnel, as well as identifying where there may be weaknesses in the personnel, if there is any.

\section{REFERENCES}

1. D. Egea, Aplicaciones para llevar el registro del control horario de los trabajadores en la pyme, 2019. [Online]. Available: https://www.sage.com/es-es/blog/cinco-aplicaciones-par a-llevar-el-registro-del-control-horario-de-los-trabajador es-en-la-pyme/. [Accessed: 05-Dec-2019].

2. A. Delgado, D. Vriclizar, and E. Medina, Artificial intelligence model based on grey systems to assess water quality from Santa river watershed, in 2017 Electronic Congress (E-CON UNI), 2017, pp. 1-4.

3. Perú21, Explotación laboral crece y no se fiscaliza, no hay cifras del trabajo forzoso, 01-Jul-2017.

4. CanalN, INEI: $\mathbf{1 1 2}$ mil limeños trabajan más de $\mathbf{1 3}$ horas al día, 17-Jun-2019.

5. S. Faranello, Balsamiq Wireframes Quickstart Guide.

6. Y. G. Ji, J. H. Park, C. Lee, and M. H. Yun, A usability checklist for the usability evaluation of mobile phone user interface, Int. J. Hum. Comput. Interact., vol. 20, no. 3, pp. 207-231, 2006.

7. D. Zhang and B. Adipat, Challenges, methodologies, and issues in the usability testing of mobile applications, Int. J. Hum. Comput. Interact., vol. 18, no. 3, pp. 293-308, 2005.

8. A. Delgado and H. Flor, Selection of the best air purifier system to urban houses using AHP, in 2017 CHILEAN Conference on Electrical, Electronics Engineering, Information and Communication Technologies, CHILECON 2017 - Proceedings, 2017, vol. 2017-January, pp. 1-4.

9. J. M. Rivero, G. Rossi, J. Grigera, J. Burella, E. R. Luna, and S. Gordillo, From mockups to user interface models: An extensible model driven approach, in Lecture Notes in Computer Science (including subseries Lecture Notes in Artificial Intelligence and Lecture Notes in Bioinformatics), 2010, vol. 6385 LNCS, pp. 13-24.

10. J. M. Rivero, G. Rossi, J. Grigera, E. Robles Luna, and A. Navarro, From interface mockups to Web application 
models, in Lecture Notes in Computer Science (including subseries Lecture Notes in Artificial Intelligence and Lecture Notes in Bioinformatics), 2011, vol. 6997 LNCS, pp. 257-264.

11. ISDI, La herramienta que te permite realizar prototipos de tus proyectos: Balsamiq, 2014. [Online]. Available:

https://www.isdi.education/es/isdigital-now/herramienta -te-permite-realizar-prototipos-de-tus-proyectos-balsami q. [Accessed: 05-Dec-2019].

12. Upper Technology, ¿Una herramienta para la creación de bocetos? Balsamiq Mockups, 2016. [Online]. Available:

https://www.uppertechnology.com/una-herramienta-para -la-creacion-de-bocetos-balsamiq-mockups/.

13. A. N. Gonzalez, ¿Qué es Android?, Xataka Android, 2011. [Online]. Available: https://www.xatakandroid.com/sistema-operativo/que-es -android. [Accessed: 05-Dec-2019].

14. K. A. Talha, D. I. Alper, and C. Aydin, APK Auditor: Permission-based Android malware detection system, Digit. Investig., vol. 13, pp. 1-14, Jun. 2015.

15. ¿Qué es la tecnología Java y para qué la necesito?, $2016 . \quad$ [Online]. Available: https://anyuska-nl13.wixsite.com/javaguia/single-post/2 013/11/30/¿Qué-es-la-tecnología-Java-y-para-qué-la-nec esito. [Accessed: 05-Dec-2019].

16. F. M. Máñez, Desarrollo de una aplicación para medición de distancias con un dispositivo Android, p. 24.

17. D. Dzvonyar, S. Krusche, and L. Alperowitz, Real projects with informal models, in CEUR Workshop Proceedings, 2014, vol. 1346, pp. 39-45.

18. T. Rajanen, Mikko; Jokela, Analysis of usability Cost-Benefit Models, 2004.

19. D. Bolchini, D. Pulido, and A. Faiola, Paper in screen prototyping: An agile technique to anticipate the mobile experience, Interactions, vol. 16, no. 4, pp. 29-33, Jul. 2009.

20. K. Lapin, Mockups and prototypes Lecture 6 ANTBOX, 2017.

21. A. Delgado, J. Maguiña, R. Cabezas, S. Hidalgo, and C. Carbajal, Integral assessment of risk level in libraries using the grey clustering method, Int. J. Recent Technol. Eng., vol. 8, no. 3, 2019.

22. S. B. Oo, N. H. M. Oo, S. Chainan, A. Thongniam, and W. Chongdarakul, Cloud-based web application with NFC for employee attendance management system, in $3 r d$ International Conference on Digital Arts, Media and Technology, ICDAMT 2018, 2018, pp. 162-167.

23. A. Delgado, A. Aguirre, E. Palomino, and G. Salazar, Applying triangular whitenization weight functions to assess water quality of main affluents of Rimac river, in Proceedings of the 2017 Electronic Congress, E-CON UNI 2017, 2017, vol. 2018-January, pp. 1-4. 